\title{
Sunflower Oil Supplementation Has Proinflammatory Effects and Does Not Reverse Insulin Resistance in Obesity Induced by High-Fat Diet in C57BL/6 Mice
}

\author{
Laureane Nunes Masi, ${ }^{1}$ Amanda Roque Martins, ${ }^{1}$ José César Rosa Neto, ${ }^{1}$ \\ Cátia Lira do Amaral, ${ }^{1}$ Amanda Rabello Crisma, ${ }^{1}$ Marco Aurélio Ramirez Vinolo, ${ }^{1}$ \\ Edson Alves de Lima Júnior, ${ }^{1}$ Sandro Massao Hirabara, ${ }^{1,2}$ and Rui Curi1 \\ ${ }^{1}$ Department of Physiology and Biophysics, Institute of Biomedical Sciences, University of São Paulo, \\ Avenu Professor Lineu Prestes, Butantã, 1524 São Paulo, SP, Brazil \\ ${ }^{2}$ Post-Graduate Program in Human Movement Sciences, Institute of Physical Activity Sciences and Sports, \\ Cruzeiro do Sul University, 05508-000 São Paulo, SP, Brazil
}

Correspondence should be addressed to Sandro Massao Hirabara, sandromh@yahoo.com.br

Received 15 June 2012; Accepted 5 August 2012

Academic Editor: Ji An Pan

Copyright (C) 2012 Laureane Nunes Masi et al. This is an open access article distributed under the Creative Commons Attribution License, which permits unrestricted use, distribution, and reproduction in any medium, provided the original work is properly cited.

\begin{abstract}
High consumption of polyunsaturated fatty acids, such as sunflower oil has been associated to beneficial effects in plasma lipid profile, but its role on inflammation and insulin resistance is not fully elucidated yet. We evaluated the effect of sunflower oil supplementation on inflammatory state and insulin resistance condition in HFD-induced obese mice. C57BL/6 male mice (8 weeks) were divided in four groups: (a) control diet (CD), (b) HFD, (c) CD supplemented with n-6 (CD + n-6), and (d) HFD supplemented with n-6 (HFD + n-6). CD + n-6 and HFD + n-6 were supplemented with sunflower oil by oral gavage at $2 \mathrm{~g} / \mathrm{Kg}$ of body weight, three times per week. CD and HFD were supplemented with water instead at the same dose. HFD induced whole and muscle-specific insulin resistance associated with increased inflammatory markers in insulin-sensitive tissues and macrophage cells. Sunflower oil supplementation was not efficient in preventing or reducing these parameters. In addition, the supplementation increased pro-inflammatory cytokine production by macrophages and tissues. Lipid profile, on the other hand, was improved with the sunflower oil supplementation in animals fed HFD. In conclusion, sunflower oil supplementation improves lipid profile, but it does not prevent or attenuate insulin resistance and inflammation induced by HFD in C57BL/6 mice.
\end{abstract}

\section{Introduction}

Occidental diet is characterized by high caloric intake, mainly saturated fatty acids and glucose consumption, contributing to the development of obesity and insulin resistance. In the past 15 years, obesity has been associated to chronic inflammation in several tissues and cells, such as liver, adipose tissue, skeletal muscle, and immune cells.

In fact, chronic and subclinical "low-grade" inflammatory state is a hallmark of obesity, and this condition has been proposed to play a central role in the development of insulin resistance, type 2 diabetes mellitus, and steatosis [1]. During the past decades, the prevalence of obesity has enormously increased worldwide [2]. A possible interaction factor between metabolic disorders and inflammation is the disruption in lipid metabolism caused by high levels of saturated fatty acids from high-fat and caloric diet $[3,4]$.

C57BL/6 mice develop obesity, insulin resistance (IR), diabetes mellitus, advanced fatty liver, and fatty pancreatic diseases when submitted to a high-fat diet (HFD), mainly enriched with saturated fatty acids [5]. The composition of fatty acids on diet can be an important modulator of lipid metabolism and inflammation. Some studies have showed that an increase in circulating levels of mono- or polyunsaturated fatty acids improves insulin sensitivity and ameliorates hepatic steatosis $[6,7]$. Sunflower oil is rich in 
mono- (MUFA) and polyunsaturated fatty acids (PUFA), mainly linoleic acid, a member of the n-6 family.

Diet enriched with sunflower oil decreases plasma triacylglycerol and has beneficial effects on plasma lipid profile [8]. Moreover, acute administration of sunflower oil in rats potentially prevents the gastric damages generated by indomethacin administration through increased anti-inflammatory response [9]. However, mice fed with sunflower oil-enriched diet present increased IL-6 (a proinflammatory cytokine) levels in white adipose tissue[8]. Thus, further studies are required to adequately determine the pro- or anti-inflammatory effects of n-6 fatty acids.

Adipose tissue, skeletal muscle, liver, and immune cells have been identified as critical targets for the disruption in metabolic and inflammatory signaling in obesity. The imbalance between metabolic alterations and inflammatory signaling pathways leads to insulin resistance, hepatic steatosis, and related diseases $[4,10]$.

In this study, we evaluated the effect of sunflower oil supplementation on inflammation and insulin sensitivity in mice fed a balanced diet and a HFD (rich in saturated fatty acids). The protecting or potentiating effect of sunflower oil supplementation on insulin resistance and inflammation was investigated. Whole body (Insulin Tolerance Test-ITT and Glucose Tolerance Test-GTT) and skeletal muscle (glucose uptake and metabolism) insulin sensitivity was examined. Inflammatory markers were investigated in liver, adipose tissue, skeletal muscle, and peritoneal macrophages. The strategy used was to investigate the effect of sunflower oil supplementation in mice fed a balanced diet and a HFD. Under this last condition, a clear inflammatory state is established and so a possible anti-inflammatory effect could be pronounced.

\section{Materials and Methods}

2.1. Animals. All animal studies were performed according to protocols approved by the Animal Care and Use Committee from the Institute of Biomedical Sciences, University of São Paulo. C57BL/6 male mice ( 8 weeks-old) were used for the study. Animals were housed in a room with light-dark cycle of $12-12 \mathrm{~h}$ and temperature of $23 \pm 2^{\circ} \mathrm{C}$. Animals were divided in four groups: (a) control diet (CD), (b) high-fat diet (HFD), (c) control diet supplemented with n-6 (CD + n-6), and (d) high-fat diet supplemented with n-6 (HFD + $\mathrm{n}-6)$. During the first 4 weeks preceding the induction of obesity by HFD, all the four experimental groups were fed $\mathrm{ad}$ libitum with a control diet (76\% carbohydrates, 9\% fat, 15\% proteins). CD + n-6 and HFD + n- 6 were supplemented with sunflower oil (n-6 PUFA source) by oral gavage at $2 \mathrm{~g}$ per $\mathrm{Kg}$ of body weight, three times per week, during 12 weeks. This dosage of oil was chosen based on previous studies using different oils from our group and others [11-13]. CD and HFD received water at the same dose.

2.2. HFD-Induced Obesity and Insulin Resistance. After the first 4 weeks, animals from the HFD and HFD + n- 6 groups received high-fat diet (26\% carbohydrates, 59\% fat, $15 \%$ proteins) during the next 8 weeks. CD and CD $+n-6$ groups remained on the control diet. Supplementation with n-6 (sunflower oil, $2 \mathrm{~g} / \mathrm{Kg}$ b.w.) was kept until the end of the 12 weeks.

2.3. Glucose and Insulin Tolerance Tests. Tolerances to glucose (GTT) and to insulin (ITT) were evaluated after $6 \mathrm{~h}$ fasting. For GTT, mice were intraperitoneally injected (i.p.) with glucose ( $2 \mathrm{~g} / \mathrm{Kg}$ body weight). Blood glucose measurements were performed at $0,15,30,45,60$, and $90 \mathrm{~min}$ after glucose injection. Glucose concentration versus time was plotted and the area under the curve (AUC) was calculated for each animal. For ITT, animals were i.p. injected with insulin (Humulin R, Lilly, $0.75 \mathrm{UI} / \mathrm{kg} \mathrm{b.w.)} \mathrm{and} \mathrm{glucose}$ measurements were performed at $0,10,20,30,40,50$, and $60 \mathrm{~min}$ after injection. Glucose concentration versus time was plotted and the glucose lowering rate was calculated.

In both tests, blood samples were collected from the tail vein. For GTT, serum glucose was measured by colorimetric assay commercially available (PAP Liquiform Glucose, Labtest) and for ITT, glucose was measured by using glucometer (One Touch Ultra, Johnson \& Johnson).

2.4. Serum Parameters Analysis. After 6 hours fasting, animals were anesthetized and blood was collected by puncturing the orbital plexus. Serum glucose, triacylglycerol, total cholesterol, LDL-cholesterol, and HDL-cholesterol were determined by colorimetric assays (Labtest Diagnostics, Lagoa Santa, MG, Brazil).

2.5. Responsiveness to Insulin in Isolated Soleus Muscle. Animals were euthanized by cervical dislocation and soleus muscles rapidly and carefully isolated, weighed (8-10 $\mathrm{mg}$ ), attached to stainless steel clips to maintain resting tension, and preincubated for $30 \mathrm{~min}$, at $37^{\circ} \mathrm{C}$, in Krebs-Ringer bicarbonate buffer (KRBB) containing $5.6 \mathrm{mM}$ glucose and $1 \%$ bovine serum albumin (BSA), pH 7.4, pregassed for $30 \mathrm{~min}$ with $95 \% \mathrm{O}_{2} / 5 \% \mathrm{CO}_{2}$, with agitation at 100 oscillations per min. After this period, muscles were transferred to other vials containing the same buffer, but added of $0.3 \mu \mathrm{Ci} / \mathrm{mL}$ D-[U$\left.{ }^{14} \mathrm{C}\right]$-glucose and $0.2 \mu \mathrm{Ci} / \mathrm{mL} 2$-deoxy-D-[2,6- $\left.{ }^{3} \mathrm{H}\right]$-glucose. Phenylethylamine $(0.2 \mathrm{~mL})$, diluted $1: 1 \mathrm{v} / \mathrm{v}$ in methanol, was added into a separate compartment for ${ }^{14} \mathrm{CO}_{2}$ adsorption. Incubation was then performed for $1 \mathrm{~h}$ under similar conditions, in the absence or presence of $7 \mathrm{nM}$ insulin. Gasification with $95 \% \quad \mathrm{O}_{2} / 5 \% \quad \mathrm{CO}_{2}$ was maintained during the preincubation and the first $15 \mathrm{~min}$ of the incubation period and then stopped.

After the incubation period, muscles were briefly washed in cold $\mathrm{KRBB}$ at $4^{\circ} \mathrm{C}$, dried on filter paper and frozen in liquid $\mathrm{N}_{2}$. Samples were processed for measurements of uptake of 2-deoxy-D-[2,6- $\left.{ }^{3} \mathrm{H}\right]$-glucose, D- $\left[{ }^{14} \mathrm{C}\right]$-glucose incorporation, $\left[{ }^{14} \mathrm{C}\right]$-glycogen synthesis, and decarboxylation of $\mathrm{D}$ - $\left[{ }^{14} \mathrm{C}\right]$-glucose, according to methods described by Challiss et al. [14], Espinal et al. [15] and Leighton et al. [16], respectively, and routinely have been used by our group [11, 17-22]. 
TABLE 1: Obesity characteristics from mice fed with control diet (CD) or high-fat diet (HFD), supplemented or not with sunflower oil (rich in n-6 fatty acids).

\begin{tabular}{lcccc}
\hline & CD & HFD & CD + n6 & HFD + n6 \\
\hline Body weight gain (g) & $2.90 \pm 0.42$ & $11.30 \pm 0.91^{*}$ & $3.99 \pm 0.65$ & $10.33 \pm 0.50^{\#}$ \\
Food ingestion (g/day/animal) & $3.61 \pm 0.091$ & $2.44 \pm 0.164^{*}$ & $4.53 \pm 0.158^{*}$ & $2.45 \pm 0.033^{\#}$ \\
Food efficiency (body weight gain (g)/food ingestion (g)) & $0.014 \pm 0.06$ & $0.083 \pm 0.022^{*}$ & $0.016 \pm 0.008$ & $0.075 \pm 0.011^{\#}$ \\
Epididymal adipose tissue (mg) & $737.9 \pm 89.4$ & $1777.0 \pm 234.3^{*}$ & $555.1 \pm 45.5$ & $1450.0 \pm 176.8^{\#}$ \\
\hline
\end{tabular}

Oral supplementation with sunflower oil rich in n-6 ( $2 \mathrm{~g} / \mathrm{Kg}$ body weight, three times a week, oral gavage) or water, started four weeks before feeding or not with HFD, maintained until the end of experimental protocol. Animals were feed with HFD or CD for additional eight weeks. Mean \pm SEM $(n=8-10)$. Data were analyzed by two-way ANOVA and Bonferroni post-test. ${ }^{*} P<0.05$ versus $\mathrm{CD}$; ${ }^{\#} P<0.05$ versus $\mathrm{CD}+\mathrm{n} 6$.

\subsection{Analysis of Inflammatory Parameters}

2.6.1. Tissue Cytokine and Adipokine Content Measurements. Mice were euthanized on $\mathrm{CO}_{2}$ chamber and visceral adipose tissue (epididymal, retroperitoneal, and mesenteric), liver, gastrocnemius muscle, and peritoneal macrophages rapidly collected. About $100 \mathrm{mg}$ of liver, gastrocnemius muscle and retroperitoneal adipose tissue were used for the determination of TNF- $\alpha$, IL- 6 , and IL-10 content. Tissues were homogenized in RIPA buffer $(0.625 \%$ Nonidet P-40, $0.625 \%$ sodium deoxycholate, $6.25 \mathrm{mM}$ sodium phosphate, and $1 \mathrm{mM}$ ethylenediamine tetra acetic acid at $\mathrm{pH} 7.4$ ), containing $10 \mathrm{~g} / \mathrm{mL}$ of a protease inhibitor cocktail (Sigma-Aldrich, St. Louis, MO, USA). Homogenates were centrifuged at $12,000 \mathrm{~g}$ for $10 \mathrm{~min}$ at $4^{\circ} \mathrm{C}$, supernatant was collected, and protein concentration determined using Bradford assay (BioRad, Hercules, CA, USA). Bovine serum albumin was used as a protein reference. Likewise, about $150 \mathrm{mg}$ of epididymal adipose tissue were cultured in DMEM sterile medium (Gibco), containing 10\% FBS, $2 \mathrm{mM}$ glutamine and antibiotics for $24 \mathrm{~h}$, at $37^{\circ} \mathrm{C}, 5 \% \mathrm{CO}_{2}$ humidified air environment. Thereafter, medium culture was collected and used for the determination of leptin, adiponectin, and resistin contents. For all determinations, we used colorimetric immunoassays ELISA (DuoSet kits, R\&D System).

2.6.2. Peritoneal Macrophage Isolation and Culture. Cytokine and nitric oxide (NO) production was evaluated in macrophages obtained by washing the peritoneal cavity with $6 \mathrm{~mL}$ RPMI culture medium (Gibco), containing 10\% FBS and $4 \mathrm{mM}$ glutamine. Macrophage-rich cultures (more than $90 \%$ of the cells were $\mathrm{F} 4 / 80^{+}$) were obtained by incubating peritoneal cells in 24-well polystyrene culture plates for $2 \mathrm{~h}$ at $37^{\circ} \mathrm{C}$ in a $5 \% \mathrm{CO}_{2}$, humidified air environment. Nonadherent cells were removed by washing with RPMI. Adherent cells were then incubated with $2.5 \mu \mathrm{g} / \mathrm{mL}$ of LPS (E. coli, serotype 0111:B4, Sigma Chemical Company, USA) for $24 \mathrm{~h}$ [23]. Medium was collected for determination of IL6 , IL-10, and TNF- $\alpha$ by ELISA, and nitrite content by Griess method [24].

2.7. Statistical Analysis. Data are presented as mean \pm SEM. All groups were compared by two-way ANOVA following Bonferroni posttests. $P<0.05$ was considered to be significant.

\section{Results}

3.1. Exposure to HFD Induces Obesity Associated with Glucose and Insulin Intolerance. Animals fed with HFD for eight weeks showed increased (by 3.8 fold) body weight gain when compared to those fed with CD. Despite reduced food ingestion, the food efficiency of HFD was 6 fold higher than CD. Moreover, epididymal adipose tissues were increased by HFD. Sunflower oil did not change body weight gain, food efficiency, or adipose tissue increased (Table 1).

HFD increased fasted glucose in $18 \%$ (Table 2). An increase of $63 \%$ in area under the curve in glucose tolerance test (GTT) was also observed in animals treated with HDF, demonstrating glucose intolerance, which was associated with insulin intolerance, as observed by the reduction in glucose clearance during insulin tolerance test (ITT). Supplementation with sunflower oil maintained fasted glucose levels similar to CD. However, the supplementation did not prevent the glucose and insulin intolerance induced by HFD. Furthermore, sunflower oil supplementation induced insulin intolerance itself ( $C D+n-6$ group), reducing the clearance of glucose similar to HFD without supplementation. Total cholesterol and LDL cholesterol levels were increased by HFD and sunflower oil supplementation in association with HFD showed protective effect in the prevention of the increased LDL cholesterol and cholesterol total levels found in HFD.

3.2. HFD Impaired Glucose Uptake and Metabolism in Soleus Muscle. Soleus muscles from animals fed with HFD did not respond to insulin stimulus in relation to glucose uptake and metabolism (Figure 1), characterizing muscle insulin resistance state. This effect was not prevented or reduced by sunflower oil supplementation. Interestingly, the supplementation itself (CD $+\mathrm{n}-6$ group) increased basal glucose uptake and glucose oxidation, but it failed to respond to the insulin stimulus when compared to the control group (CD group).

\subsection{HFD and Sunflower Oil Supplementation Induced} Inflammation. Peritoneal macrophages stimulated with LPS showed increased production of nitrite, TNF $\alpha$, IL6, and IL10 when compared with unstimulated cells (Figure 2). Macrophages from animals with obesity induced by HFD for 8 weeks showed a inflammatory profile, with increased production of nitrite, TNF- $\alpha$, and IL- 6 , associated with decreased content of IL-10 when stimulated with LPS. 
TABLE 2: Metabolic parameters from mice fed with control diet (CD) or high-fat diet (HFD), supplemented, or not with sunflower oil (rich in $n-6$ fatty acids).

\begin{tabular}{lcccc}
\hline & CD & HFD & CD + n6 & HFD + n6 \\
\hline Fasted glucose (mg/dL) & $186.1 \pm 5.66$ & $221.0 \pm 8.38^{*}$ & $173.8 \pm 4.75$ & $196.8 \pm 10.66$ \\
GTT test (AUC) & $7987 \pm 779.3$ & $13090 \pm 643.9^{*}$ & $7568 \pm 1359$ & $14790 \pm 1731^{\#}$ \\
ITT test $(\%$ glucose/min) & $2.97 \pm 0.19$ & $2.13 \pm 0.21^{*}$ & $1.94 \pm 0.30^{*}$ & $1.98 \pm 0.22$ \\
Total cholesterol (mg/dL) & $148.2 \pm 6.72$ & $192.7 \pm 11.96^{*}$ & $164.3 \pm 14.00$ & $166.3 \pm 12.33$ \\
LDL cholesterol (mg/dL) & $127.4 \pm 5.15$ & $165.1 \pm 14.49^{*}$ & $128.2 \pm 13.77$ & $136.7 \pm 13.22$ \\
HDL cholesterol (mg/dL) & $14.73 \pm 0.83$ & $15.52 \pm 1.86$ & $19.33 \pm 2.21$ & $15.00 \pm 1.15$ \\
Triglycerides (mg/dL) & $68.61 \pm 5.56$ & $63.00 \pm 4.40$ & $84.70 \pm 8.53$ & $72.78 \pm 8.71$ \\
\hline
\end{tabular}

Oral supplementation with n-6 (2 g/Kg body weight, three times a week, gavage) or water have started four weeks before HFD and continued until the end of experimental period. Animals were fed HFD or CD for eight weeks. GTT: glucose tolerance test; ITT: insulin tolerance test. Mean \pm SEM $(n=6-15)$. ANOVA two-way with Bonferroni post tests. ${ }^{*} P<0.05$ when compared with $\mathrm{CD} ;{ }^{*} P<0.05$ when compared with $\mathrm{CD}+\mathrm{n} 6$.

TABLE 3: Adipokine production in adipose tissue from mice fed with control diet (CD) or high-fat diet (HFD), supplemented, or not with sunflower oil (rich in n-6 fatty acids).

\begin{tabular}{lcccc}
\hline & CD & HFD & CD + n6 & HFD + n6 \\
\hline Epididymal adipose tissue $^{\mathrm{a}}$ & & & & \\
$\quad$ Leptin & $42.51 \pm 8.75$ & $81.38 \pm 9.90^{*}$ & $62.42 \pm 8.80$ & $88.03 \pm 10.96$ \\
Adiponectin & $659.9 \pm 39.94$ & $697.6 \pm 43.85$ & $730.3 \pm 76.68$ & $649.8 \pm 45.38$ \\
Resistin & $625.1 \pm 100.8$ & $528.6 \pm 71.65$ & $913.0 \pm 181.0$ & $327.0 \pm 42.15^{\#}$ \\
\hline
\end{tabular}

Oral supplementation with $\mathrm{n}-6(2 \mathrm{~g} / \mathrm{Kg}$ body weight, three times a week, gavage) or water started four weeks before HFD and continued until the end of experiment. Animals were feed with HFD or CD for eight weeks. Approximately $150 \mathrm{mg}$ of tissue were incubated in DMEM medium for $24 \mathrm{~h}$ and the supernatant were used for measures. Mean $\pm \operatorname{SEM}(n=7-11)$. ANOVA two-way with Bonferroni post tests. ${ }^{*} P<0.05$ when compared with CD; ${ }^{\#} P<0.05$ when compared with $\mathrm{CD}+\mathrm{n} 6 .{ }^{\mathrm{a}}$ Values are expressed as $\mathrm{pg} / \mathrm{mL} / \mathrm{mg}$ tissue.

Interestingly, supplementation with sunflower oil induced similar inflammatory response in macrophages. For TNF$\alpha$ only, the association of HFD and n- 6 supplementation (HFD $+\mathrm{n}-6$ group) showed beneficial response, decreasing this cytokine production.

In general, HFD induced and increase in the proinflammatory cytokine IL6 and decrease in the antiinflammatory cytokine IL10 contents in the insulin target tissues (liver, skeletal muscle, and adipose tissue; Figure 3). Interesting, sunflower oil supplementation itself $(\mathrm{CD}+$ n-6 group) for 12 weeks increased the content of the proinflammatory cytokine IL6 in all tissues. However, when the sunflower oil was associated with HFD (HFD + n-6 group), cytokine concentrations were similar to that found in the HFD group, in liver and adipose tissue.

Adipokines production by epididymal adipose tissue was determined after $24 \mathrm{~h}$ culture. Adipose tissues from HFD animals showed increased production of leptin (Table 3 ). Resistin was reduced only when HFD was associated to sunflower oil supplementation (HFD $+\mathrm{n}-6$ group) in comparison to $\mathrm{CD}+\mathrm{n} 6$ group.

\section{Discussion}

This is the first study to investigate the effects of sunflower oil supplementation on inflammation and insulin sensitivity in mice fed a balanced diet and a HFD. We showed that HFD induces decreased glucose tolerance (as demonstrated by GTT) and insulin sensitivity (as observed in ITT) in the whole body. Surprisingly, this last effect was also verified in the $\mathrm{CD}+\mathrm{n} 6$ group. Moreover, proinflammatory response was increased in the HFD group without prevention or attenuation by sunflower oil supplementation. This effect was also observed in $\mathrm{CD}+\mathrm{n} 6$ group. Lipid profile was impaired by HFD. Animals from HFD group showed an increase in total and LDL cholesterol plasma levels. These alterations were ameliorated by sunflower oil supplementation (HFD $+n 6$ group).

HFD has been associated with insulin resistance and inflammatory condition, contributing to the development of several related diseases, such as obesity, diabetes mellitus type 2, metabolic syndrome, cancer, and cardiovascular diseases [25-27]. Various strategies have been investigated in order to decreasing insulin resistance and inflammation, including natural and modified compounds, cyclooxygenase inhibitors, and physical exercise [28-35]. Since skeletal muscle tissue represents $50-60 \%$ of the body weight and it is the main insulin-responsive tissue in association to liver and adipose tissue, it has been proposed that skeletal muscle dysfunctions (reduced oxidative capacity and impaired insulin sensitivity) play a central role in the abnormalities of chronic diseases [21, 36-40]. In this work, we investigated the effect of sunflower oil supplementation on insulin sensitivity (in whole animal in vivo and in soleus muscle in vivo) and inflammatory condition (liver, skeletal muscle, adipose tissue) in mice fed a balanced diet and a HFD. In recent study, Bjermo et al. [41] showed that isocaloric diet with n-6 


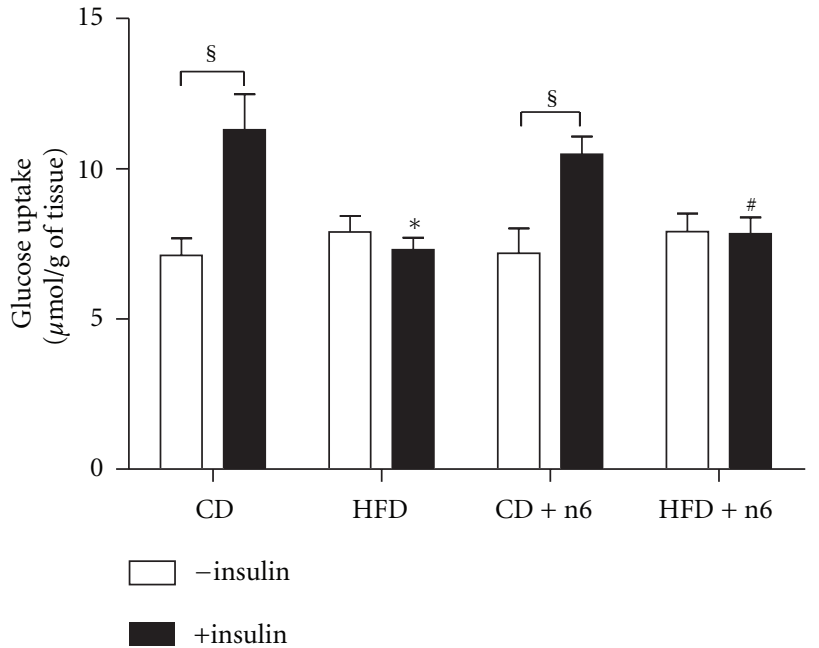

(a)

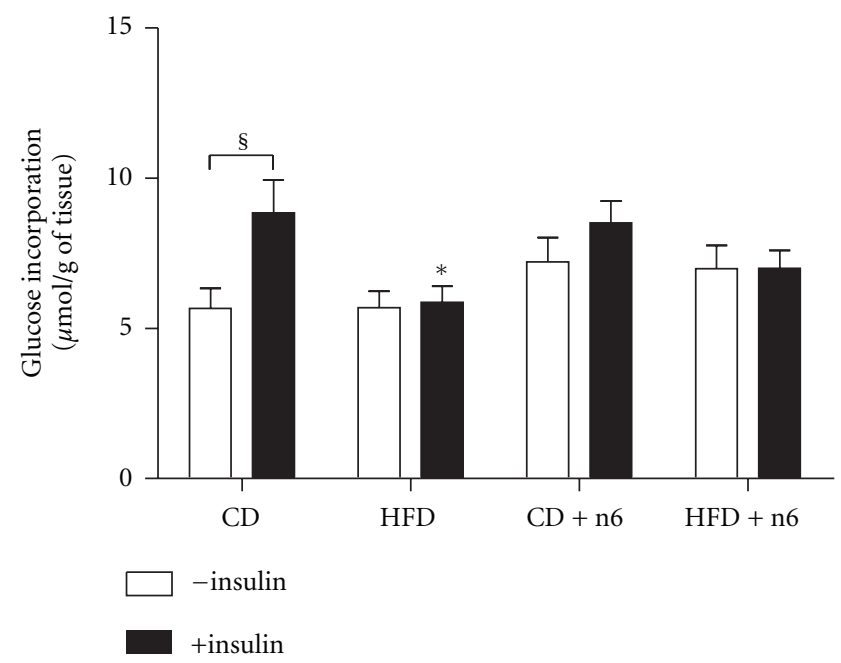

(c)

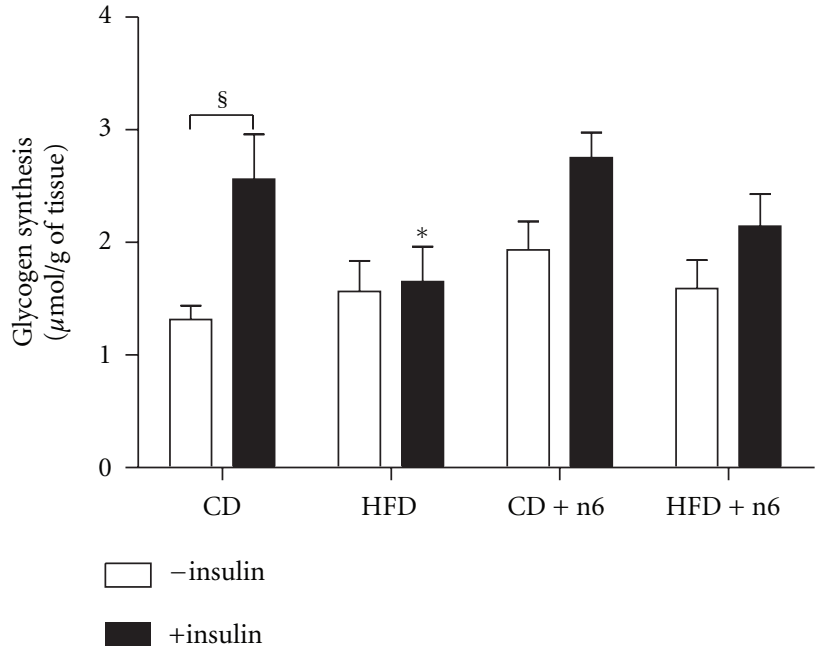

(b)

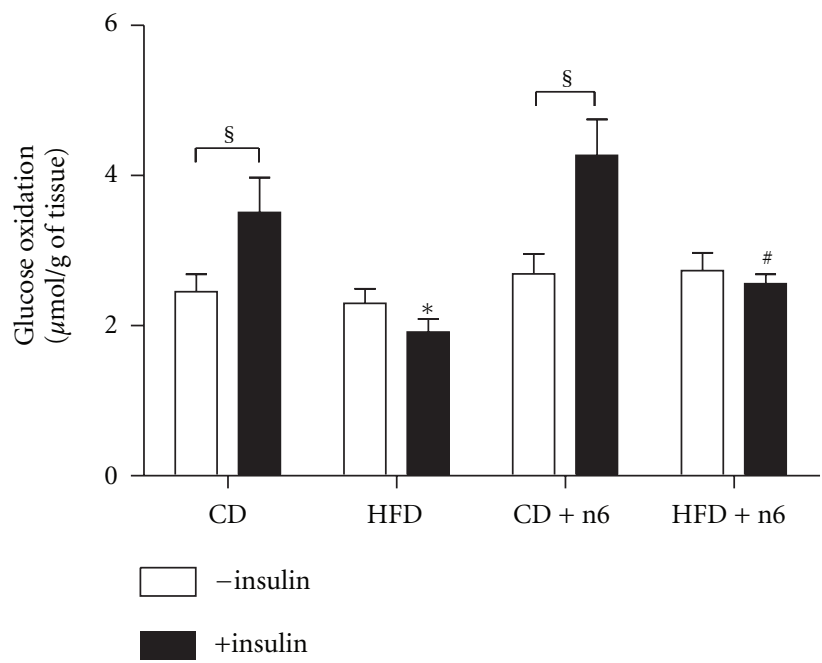

(d)

FIGURE 1: Effect of sunflower oil supplementation (rich in n-6 fatty acids) on glucose uptake and metabolism in isolated soleus muscle from C57BL/6 mice. The muscles were incubated in Krebs Ringer buffer, containing $5.6 \mathrm{mM}$ glucose, $0.3 \mu \mathrm{Ci} / \mathrm{mL}$ of $\left[\mathrm{U}-{ }^{14} \mathrm{C}\right]-\mathrm{D}$-glucose and $0.2 \mu \mathrm{Ci} / \mathrm{mL}$ of 2 -deoxy-[2,6- $\left.{ }^{3} \mathrm{H}\right]$-D-glucose, in the absence (white bars) or presence (black bars) of $7 \mathrm{nM}$ insulin, for one hour. At the end of the incubation period, muscles were proceeded to analyze glucose uptake and metabolism as described in Materials and Methods. Results are presented as mean \pm SEM $(n=10-16)$. Two-way ANOVA and Bonferroni posttest were used for statistical analysis. ${ }^{\S} P<0.05$ versus the insulin stimulated (+insulin) of the same group; ${ }^{*} P<0.05$ versus $C D$ with insulin; ${ }^{\#} P<0.05$ versus $C D+$ n6 with insulin.

PUFA for 10 weeks reduce liver fat and modestly improves metabolic conditions, without weight loss in humans. In addition, it has been proposed that n-6 PUFA reduce risks of cardiovascular diseases, by improving lipid profile [42] This improvement in lipid profile was found in our study, whereas HFD + n6 group showed decreased plasma LDL and total cholesterol levels.

Some studies have shown that n-6 PUFA intake positively correlate with obesity and insulin resistance $[43,44]$. Treatment with subcutaneous injection of sunflower oil by 7 days in Wistar rats impaired insulin sensitivity by decreasing glucose clearance during ITT and GLUT-4 expression and translocation in white adipose tissue (WAT), with no effect in skeletal muscle [7]. In the $\mathrm{CD}+\mathrm{n} 6$ group, KiTT was reduced, but glucose uptake and metabolism in isolated soleus muscles were not altered after insulin stimulus. These results suggest that sunflower oil supplementation per se is not able to impair insulin response in skeletal muscle, but it possibly reduces total insulin sensitivity by decreasing the response to the hormone in other tissues, such as liver and adipose tissue. This proposition has to be investigated in further studies. In addition, both groups fed with HDF (HFD and HFD + n6 groups) showed skeletal muscle resistance to insulin, showing no beneficial effects of n-6 PUFA on peripheral insulin sensitivity.

Obesity is accompanied by a chronic low grade subclinical inflammation promoted by an increase in fuel availability, leading to infiltration of macrophages into adipose tissue. 


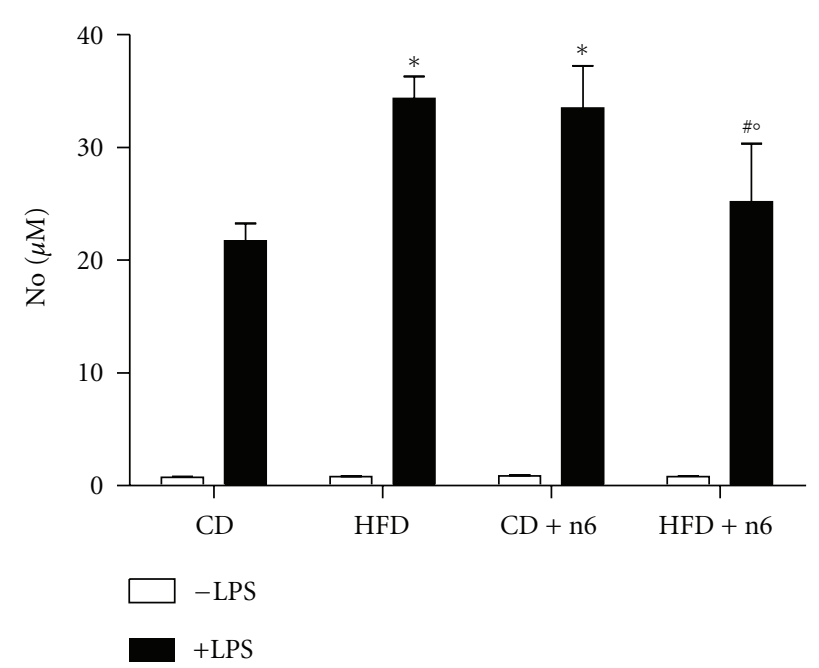

(a)

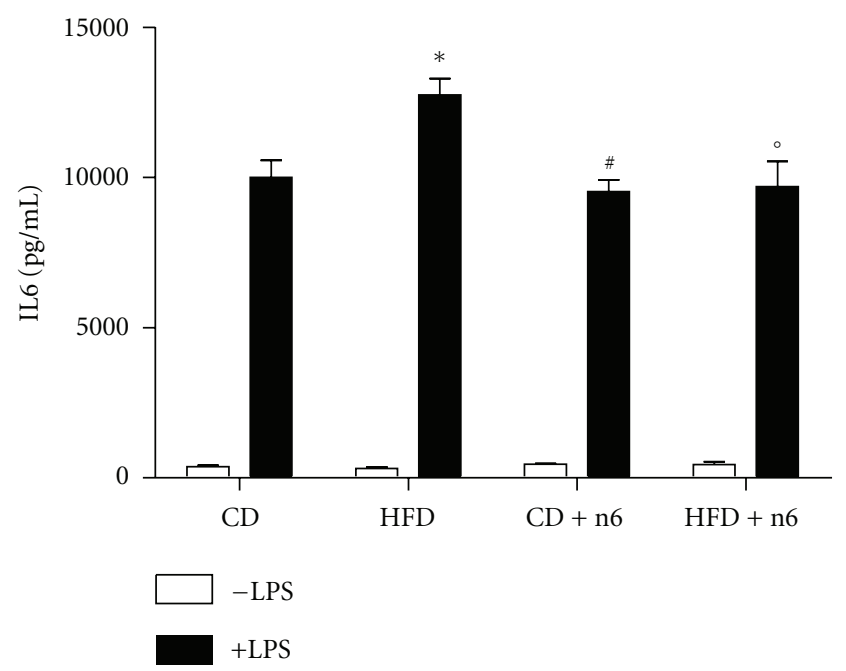

(c)

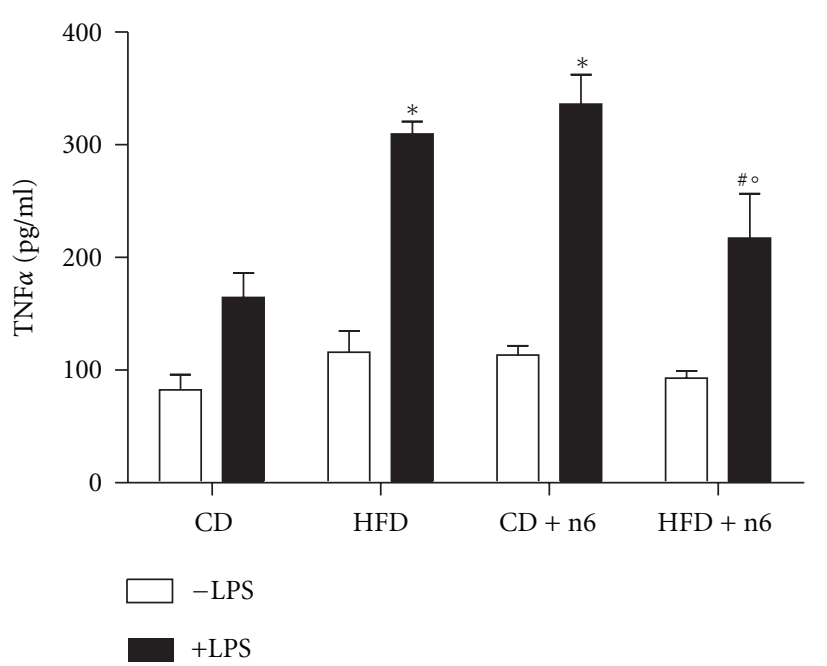

(b)

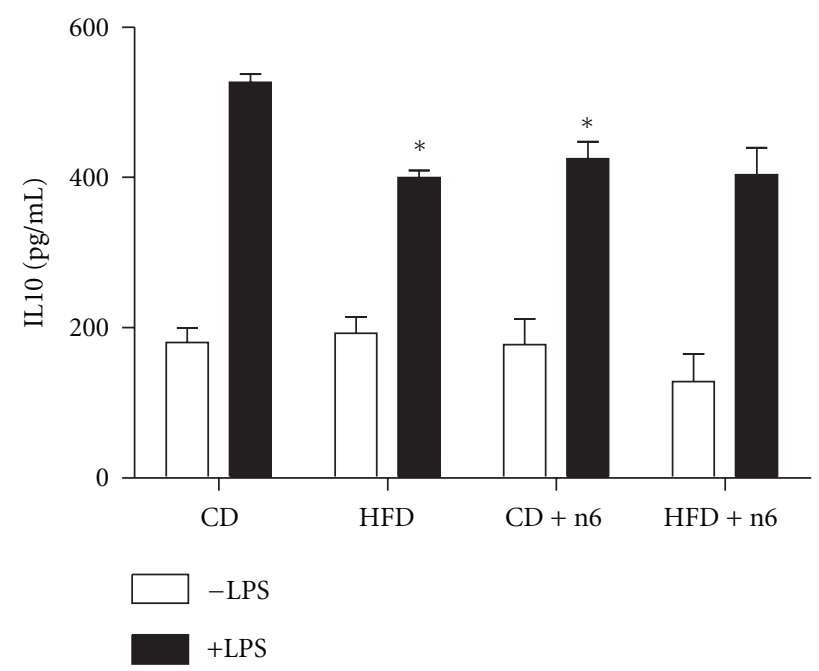

(d)

FIGURE 2: Nitric oxide and cytokine production in peritoneal macrophages collected from mice fed with control diet (CD) or high-fat diet (HFD), supplemented or not with sunflower oil (rich in n-6 fatty acids, $2 \mathrm{~g} / \mathrm{Kg}$ b.w., three times a week, by oral gavage). Animals were fed with HFD or CD for eight weeks. Peritoneal macrophages were collected and cultured for $24 \mathrm{~h}$ in the absence (white bars) or presence (black bars) of $2.5 \mu \mathrm{g} / \mathrm{mL}$ LPS. Nitric oxide (a), TNF- $\alpha$ (b), IL-6 (c), and IL-10 (d) were measured as described in Material and Methods. Total number of cells in peritoneal exudates was not different among the groups (data not shown). Data are presented as mean \pm SEM $(n=5-10)$. The CD + n6 group had just 5 samples up to the detection limit in the TNF- $\alpha$ assay. Two-way ANOVA and Bonferroni post-test were used for statistical analysis. All LPS stimulated conditions were different from unstimulated; ${ }^{*} P<0.05$ versus CD with LPS; ${ }^{\#} P<0.05$ versus $\mathrm{CD}+\mathrm{n} 6$ with $\mathrm{LPS} ;{ }^{\circ} \mathrm{P}<0.05$ versus HFD with LPS.

This condition results in enhanced inflammatory response, which stimulates the production of cytokines by adipose tissue [45]. Moreover, in obesity, increased lipotoxicity caused by high nonesterified fatty acids (NEFA) available, and triacylglycerol content leads to an increase in inflammatory markers and cytokine production in multiple organs [46, 47]. NEFA increases inflammatory response by activating TLR-4 [48]. HFD increased inflammatory response in macrophages, showing high content of IL- 6 , TNF- $\alpha$, and $\mathrm{NO}$, and low content of IL-10 (anti-inflammatory cytokine) when compared to the control group. In peripheral tissues, IL-6 content was increased in the liver and gastrocnemius muscle whereas IL-10 content was decreased in liver and retroperitoneal adipose tissue. Adipose tissue showed increased production of leptin in the HFD and HFD + $\mathrm{n} 6$ groups, compared with mice fed with control diet, and resistin was reduced in the HFD + n6 group compared with $\mathrm{CD}+\mathrm{n} 6$, in epididymal adipose tissue. Whereas in retroperitoneal adipose tissue, IL-6 was elevated in the HFD and $\mathrm{CD}+\mathrm{n} 6$ groups compared with $\mathrm{CD}$, IL-10 was reduced 


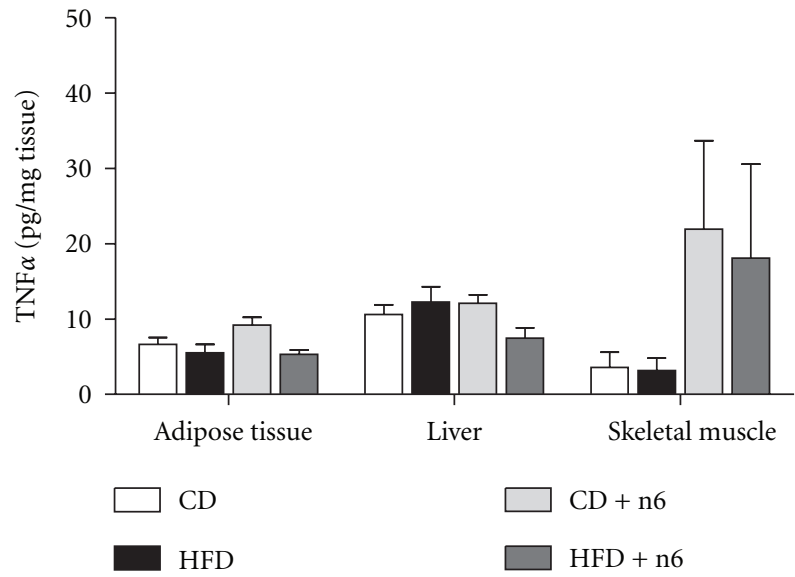

(a)

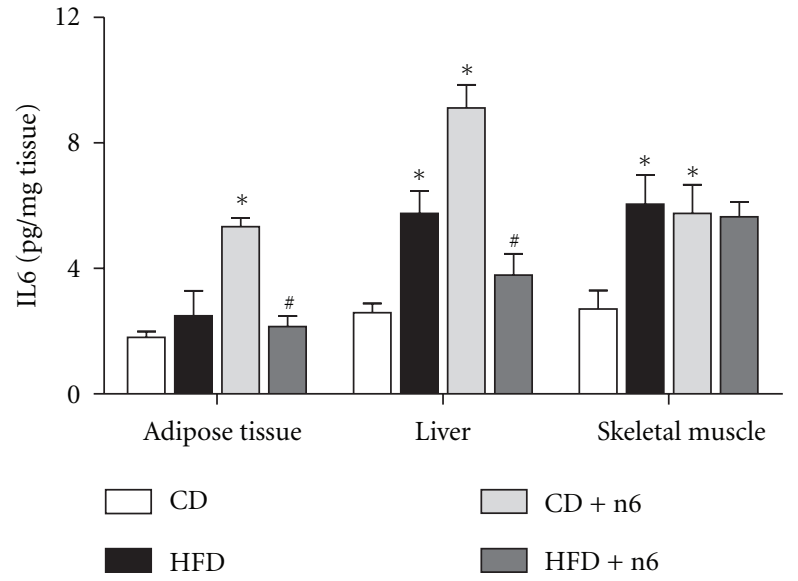

(b)

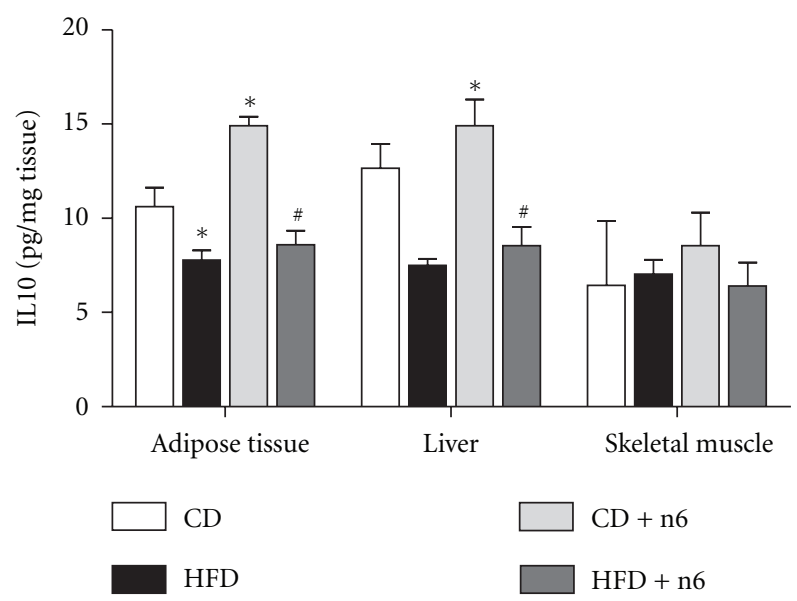

(c)

FIgURE 3: Tissue cytokine concentrations of TNF $\alpha$ (a), IL6 (b), and IL10 (c) in adipose tissue (retroperitoneal), liver, and gastrocnemius skeletal muscle from mice treated with control diet (CD) or high-fat diet (HFD), supplemented or not with sunflower oil (rich in n-6 fatty acids). Oral supplementation with n-6 ( $2 \mathrm{~g} / \mathrm{Kg}$ body weight, three times a week, gavage) or water started four weeks before HFD and continued until the end of experiment. Animals were feed with HFD or CD for eight weeks. Cytokines were measured in tissue homogenate. Values are expressed as $\mathrm{pg} / \mathrm{mg}$ protein. Mean \pm SEM $(n=4-6)$. The statistical analysis was performed using two-way ANOVA with Bonferroni post tests. ${ }^{*} P<0.05$ when compared with $\mathrm{CD} ;{ }^{\#} P<0.05$ when compared with $\mathrm{CD}+\mathrm{n} 6$.

in the HFD and CD $+\mathrm{n} 6$, and adiponectin was reduced only in $\mathrm{CD}+\mathrm{n} 6$. These results showed the inflammatory characteristics the sunflower oil supplementation and the high fatty diet fed.

Our results showed that sunflower oil supplementation causes a clear pro-inflammatory response in mice fed on control diet and it does not have additive or prophylactic effects in mice fed on HFD. Fatty acid effects on immune system have been studied since 1970's decade [49]. Linoleic acid is an essential fatty acid that leads to inflammatory response by increasing arachidonic acid production, a fatty acid related to elevated pro-inflammatory mediator generation [50]. High intake of linoleic acid has been associated to the development of chronic diseases in several studies [51, 52]. However, few studies have been carried out on the direct effect of this fatty acid on inflammatory markers [53].
In conclusion, our results showed that sunflower oil supplementation has pro-inflammatory effects in macrophages and insulin-sensitive peripheral tissues and induced insulin resistance in vivo and in vitro. These effects were demonstrated in mice fed a balanced diet and pronounced in mice fed a HFD. Interestingly, sunflower oil supplementation partially prevented the dislipidemia found in mice submitted to HFD, but it did not improve or even worsened inflammatory state and insulin resistance induced by this diet.

\section{Acknowledgments}

The authors declare no conflict of interests. This study was supported by Grants from São Paulo Research Foundation (FAPESP), Coordination for the Improvement of Higher Level Personnel (CAPES), National Council for Scientific 
and Technological Development (CNPq)/National Institute of Science and Technology in Obesity and Diabetes (INOD), Center of Lipid Research and Education (CLEaR), and Dean's Office for Research/University of São Paulo.

\section{References}

[1] P. J. White, M. Arita, R. Taguchi, J. X. Kang, and A. Marette, "Transgenic restoration of long-chain $n-3$ fatty acids in insulin target tissues improves resolution capacity and alleviates obesity-linked inflammation and insulin resistance in high-fat-fed mice," Diabetes, vol. 59, no. 12, pp. 3066-3073, 2010.

[2] R. H. Eckel, S. M. Grundy, and P. Z. Zimmet, "The metabolic syndrome," Lancet, vol. 365, no. 9468, pp. 1415-1428, 2005.

[3] H. N. Ginsberg, Y. L. Zhang, and A. Hernandez-Ono, "Metabolic syndrome: focus on dyslipidemia," Obesity, vol. 14, supplement 1, pp. 41S-49S, 2006.

[4] H. Cao, K. Gerhold, J. R. Mayers, M. M. Wiest, S. M. Watkins, and G. S. Hotamisligil, "Identification of a Lipokine, a lipid hormone linking adipose tissue to systemic metabolism," Cell, vol. 134, no. 6, pp. 933-944, 2008.

[5] M. Catta-Preta, M. A. Martins, T. M. Cunha Brunini, A. C. Mendes-Ribeiro, C. A. Mandarim-de-Lacerda, and M. B. Aguila, "Modulation of cytokines, resistin, and distribution of adipose tissue in C57BL/6 mice by different high-fat diets," Nutrition, vol. 28, no. 2, pp. 212-219, 2012.

[6] M. Sekiya, N. Yahagi, T. Matsuzaka et al., "Polyunsaturated fatty acids ameliorate hepatic steatosis in obese mice by SREBP-1 suppression," Hepatology, vol. 38, no. 6, pp. 15291539, 2003.

[7] A. C. Poletto, G. F. Anhê, P. Eichler et al., "Soybean and sunflower oil-induced insulin resistance correlates with impaired GLUT4 protein expression and translocation specifically in white adipose tissue," Cell Biochemistry and Function, vol. 28, no. 2, pp. 114-121, 2010.

[8] F. Laugerette, C. Vors, N. Peretti, and M. C. Michalski, "Complex links between dietary lipids, endogenous endotoxins and metabolic inflammation," Biochimie, vol. 93, no. 1, pp. 39-45, 2011.

[9] F. Odabasoglu, Z. Halici, A. Cakir et al., "Beneficial effects of vegetable oils (corn, olive and sunflower oils) and $\alpha$ tocopherol on anti-inflammatory and gastrointestinal profiles of indomethacin in rats," European Journal of Pharmacology, vol. 591, no. 1-3, pp. 300-306, 2008.

[10] A. Kontrogianni-Konstantopoulos, G. Benian, and H. Granzier, "Advances in muscle physiology and pathophysiology," Journal of Biomedicine and Biotechnology, vol. 2010, Article ID 780417, 1 pages, 2010.

[11] M. A. Vinolo, H. G. Rodrigues, W. T. Festuccia et al., "Tributyrin attenuates obesity-associated inflammation and insulin resistance in high-fat fed mice," American Journal of Physiology-Endocrinology and Metabolism, vol. 303, no. 2, pp. E272E282, 2012.

[12] L. A. Muehlmann, A. L. Zanatta, C. L. A. Farias et al., "Dietary supplementation with soybean lecithin increases pulmonary PAF bioactivity in asthmatic rats," Journal of Nutritional Biochemistry, vol. 21, no. 6, pp. 532-537, 2010.

[13] J. Aikawa, K. D. Moretto, F. Denes et al., "Glucose metabolism by lymphocytes, macrophages, and tumor cells from Walker 256 tumor-bearing rats supplemented with fish oil for one generation," Cell Biochemistry and Function, vol. 26, no. 8, pp. 874-880, 2008.
[14] R. A. J. Challiss, F. J. Lozeman, B. Leighton, and E. A. Newsholme, "Effects of the $\beta$-adrenoceptor agonist isoprenaline on insulin-sensitivity in soleus muscle of the rat," Biochemical Journal, vol. 233, no. 2, pp. 377-381, 1986.

[15] J. Espinal, G. L. Dohm, and E. A. Newsholme, "Sensitivity to insulin of glycolysis and glycogen synthesis of isolated soleusmuscle strips from sedentary, exercised and exercise-trained rats," Biochemical Journal, vol. 212, no. 2, pp. 453-458, 1983.

[16] B. Leighton, L. Budohoski, and F. J. Lozeman, "The effect of prostaglandins E1, E2 and F2 $(\alpha)$ and indomethacin on the sensitivity of glycolysis and glycogen synthesis to insulin in stripped soleus muscles of the rat," Biochemical Journal, vol. 227, no. 1, pp. 337-340, 1985.

[17] S. Massao Hirabara, C. R. De Oliveira Carvalho, J. R. Mendonça, E. Piltcher Haber, L. C. Fernandes, and R. Curi, "Palmitate acutely raises glycogen synthesis in rat soleus muscle by a mechanism that requires its metabolization (Randle cycle)," FEBS Letters, vol. 541, no. 1-3, pp. 109-114, 2003.

[18] M. A. Carvalho-Filho, M. Ueno, S. M. Hirabara et al., "Snitrosation of the insulin receptor, insulin receptor substrate 1 , and protein kinase B/Akt: a novel mechanism of insulin resistance," Diabetes, vol. 54, no. 4, pp. 959-967, 2005.

[19] S. M. Hirabara, L. R. Silveira, L. C. Alberici et al., "Acute effect of fatty acids on metabolism and mitochondrial coupling in skeletal muscle," Biochimica et Biophysica Acta, vol. 1757, no. 1, pp. 57-66, 2006.

[20] D. M. L. Tsukumo, M. A. Carvalho-Filho, J. B. C. Carvalheira et al., "Loss-of-function mutation in toll-like receptor 4 prevents diet-induced obesity and insulin resistance," Diabetes, vol. 56, no. 8, pp. 1986-1998, 2007.

[21] S. M. Hirabara, R. Curi, and P. Maechler, "Saturated fatty acidinduced insulin resistance is associated with mitochondrial dysfunction in skeletal muscle cells," Journal of Cellular Physiology, vol. 222, no. 1, pp. 187-194, 2010.

[22] A. M. Caricilli, P. K. Picardi, L. L. de Abreu et al., "Gut microbiota is a key modulator of insulin resistance in TLR 2 knockout mice," PLoS Biology, vol. 9, no. 12, article e1001212, 2011.

[23] J. M. Papadimitriou and I. Van Bruggen, "The effects of malnutrition on murine peritoneal macrophages," Experimental and Molecular Pathology, vol. 49, no. 2, pp. 161-170, 1988.

[24] N. P. Sen and B. Donaldson, "Improved colorimetric method for determining nitrate and nitrate in foods," Journal of the Association of Official Analytical Chemists, vol. 61, no. 6, pp. 1389-1394, 1978.

[25] C. Fernandes-Santos, R. Evangelista Carneiro, L. De Souza Mendonca, M. Barbosa Águila, and C. Alberto Mandarim-DeLacerda, "Rosiglitazone aggravates nonalcoholic fatty pancreatic disease in C57BL/6 mice fed high-fat and high-sucrose diet," Pancreas, vol. 38, no. 3, pp. e80-e86, 2009.

[26] J. C. Fraulob, R. Ogg-Diamantino, C. Fernandes-Santos, M. B. Aguila, and C. A. Mandarim-de-Lacerda, "A mouse model of metabolic syndrome: insulin resistance, fatty liver and Non-Alcoholic Fatty Pancreas Disease (NAFPD) in C57BL/6 mice fed a high fat diet," Journal of Clinical Biochemistry and Nutrition, vol. 46, no. 3, pp. 212-223, 2010.

[27] G. D. Pimentel, A. P. Dornellas, J. C. Rosa et al., "High-fat diets rich in soy or fish oil distinctly alter hypothalamic insulin signaling in rats," The Journal of Nutritional Biochemistry, vol. 23, no. 7, pp. 822-828, 2012.

[28] B. Zhou, Y. Pan, Z. Hu et al., "All-trans-retinoic acid ameliorated high fat diet-induced atherosclerosis in rabbits by inhibiting platelet activation and inflammation," Journal of 
Biomedicine and Biotechnology, vol. 2012, Article ID 259693, 9 pages, 2012.

[29] F. Rivera-Ramirez, G. N. Escalona-Cardoso, L. GarduñoSiciliano et al., "Antiobesity and hypoglycaemic effects of aqueous extract of Ibervillea sonorae in mice fed a high-fat diet with fructose," Journal of Biomedicine and Biotechnology, vol. 2011, Article ID 968984, 6 pages, 2011.

[30] J. B. Driban, A. E. Barr, M. Amin, M. R. Sitler, and M. F. Barbe, "Joint inflammation and early degeneration induced by high-force reaching are attenuated by ibuprofen in an animal model of work-related musculoskeletal disorder," Journal of Biomedicine and Biotechnology, vol. 2011, Article ID 691412, 17 pages, 2011.

[31] E. J. Yang, J. Y. Moon, J. S. Lee, J. Koh, N. H. Lee, and C. G. Hyun, "Acanthopanax koreanum fruit waste inhibits lipopolysaccharide-induced production of nitric oxide and prostaglandin $\mathrm{E}_{2}$ in RAW 264.7 macrophages," Journal of Biomedicine and Biotechnology, vol. 2010, Article ID 715739, 10 pages, 2010.

[32] K. R. Kim, C. K. Jeong, K. K. Park et al., "Anti-inflammatory effects of licorice and roasted licorice extracts on TPA-induced acute inflammation and collagen-induced arthritis in mice," Journal of Biomedicine and Biotechnology, vol. 2010, Article ID 709378, 8 pages, 2010.

[33] T. Klangjareonchai and C. Roongpisuthipong, "The effect of Tinospora crispa on serum glucose and insulin levels in patients with type 2 diabetes mellitus," Journal of Biomedicine and Biotechnology, vol. 2012, Article ID 808762, 4 pages, 2012.

[34] C. Brandt and B. K. Pedersen, "The role of exercise-induced myokines in muscle homeostasis and the defense against chronic diseases," Journal of Biomedicine and Biotechnology, vol. 2010, Article ID 520258, 6 pages, 2010.

[35] S. A. Hopkins, J. C. Baldi, W. S. Cutfield, L. McCowan, and P. L. Hofman, "Exercise training in pregnancy reduces offspring size without changes in maternal insulin sensitivity," Journal of Clinical Endocrinology and Metabolism, vol. 95, no. 5, pp. 2080-2088, 2010.

[36] M. A. Abdul-Ghani and R. A. DeFronzo, "Pathogenesis of insulin resistance in skeletal muscle," Journal of Biomedicine and Biotechnology, vol. 2010, Article ID 476279, 19 pages, 2010.

[37] M. Peppa, C. Koliaki, P. Nikolopoulos, and S. A. Raptis, "Skeletal muscle insulin resistance in endocrine disease," Journal of Biomedicine and Biotechnology, vol. 2010, Article ID 527850, 13 pages, 2010.

[38] A. R. Martins, R. T. Nachbar, R. Gorjao et al., "Mechanisms underlying skeletal muscle insulin resistance induced by fatty acids: importance of the mitochondrial function," Lipids in Health and Disease, vol. 11, article 30, 2012.

[39] K. Das, K. Das, P. S. Mukherjee et al., "Nonobese population in a developing country has a high prevalence of nonalcoholic fatty liver and significant liver disease," Hepatology, vol. 51, no. 5, pp. 1593-1602, 2010.

[40] S. Sakuma, Y. Nishioka, R. Imanishi et al., "cis9, trans11conjugated linoleic acid differentiates mouse 3T3-L1 preadipocytes into mature small adipocytes through induction of peroxisome proliferator-activated receptor $\gamma$," Journal of Clinical Biochemistry and Nutrition, vol. 47, no. 2, pp. 167$173,2010$.

[41] H. Bjermo, D. Iggman, J. Kullberg et al., "Effects of $n-6$ PUFAs compared with SFAs on liver fat, lipoproteins, and inflammation in abdominal obesity: a randomized controlled trial," The American Journal of Clinical Nutrition, vol. 95, no. 5, pp. 1003-1012, 2012.
[42] S. Czernichow, D. Thomas, and E. Bruckert, " $N-6$ fatty acids and cardiovascular health: dietary intake recommendations," Medecine/Sciences, vol. 27, no. 6-7, pp. 614-618, 2011.

[43] G. Ailhaud, F. Massiera, P. Weill, P. Legrand, J. M. Alessandri, and P. Guesnet, "Temporal changes in dietary fats: role of $n-6$ polyunsaturated fatty acids in excessive adipose tissue development and relationship to obesity," Progress in Lipid Research, vol. 45, no. 3, pp. 203-236, 2006.

[44] C. M. Phillips, L. Goumidi, S. Bertrais et al., "Leptin receptor polymorphisms interact with polyunsaturated fatty acids to augment risk of insulin resistance and metabolic syndrome in adults," Journal of Nutrition, vol. 140, no. 2, pp. 238-244, 2010.

[45] R. Stienstra, J. A. van Diepen, C. J. Tack et al., "Inflammasome is a central player in the induction of obesity and insulin resistance," Proceedings of the National Academy of Sciences of the United States of America, vol. 108, no. 37, pp. 15324-15329, 2011.

[46] H. Ghanim, A. Aljada, D. Hofmeyer, T. Syed, P. Mohanty, and P. Dandona, "Circulating mononuclear cells in the obese are in a proinflammatory state," Circulation, vol. 110, no. 12, pp. 1564-1571, 2004.

[47] M. Jové, A. Planavila, J. C. Laguna, and M. Vázquez-Carrera, "Palmitate-induced interleukin 6 production is mediated by protein kinase $\mathrm{C}$ and nuclear-factor $\mathrm{B}$ activation and leads to glucose transporter 4 down-regulation in skeletal muscle cells," Endocrinology, vol. 146, no. 7, pp. 3087-3095, 2005.

[48] M. Tschöp and G. Thomas, "Fat fuels insulin resistance through Toll-like receptors," Nature Medicine, vol. 12, no. 12, pp. 1359-1361, 2006.

[49] H. G. Rodrigues, M. A. R. Vinolo, J. Magdalon et al., "Dietary free oleic and linoleic acid enhances neutrophil function and modulates the inflammatory response in rats," Lipids, vol. 45, no. 9, pp. 809-819, 2010.

[50] M. M. Zaman, C. R. Martin, C. Andersson et al., "Linoleic acid supplementation results in increased arachidonic acid and eicosanoid production in CF airway cells and in cftr-/transgenic mice," American Journal of Physiology, vol. 299, no. 5, pp. L599-L606, 2010.

[51] A. P. Simopoulos, "Evolutionary aspects of diet, the omega6/omega-3 ratio and genetic variation: nutritional implications for chronic diseases," Biomedicine and Pharmacotherapy, vol. 60, no. 9, pp. 502-507, 2006.

[52] W. E. M. Lands, "Dietary fat and health: the evidence and the politics of prevention: careful use of dietary fats can improve life and prevent disease," Annals of the New York Academy of Sciences, vol. 1055, pp. 179-192, 2005.

[53] K. L. Fritsche, "Too much linoleic acid promotes inflammation-doesn't it?" Prostaglandins Leukotrienes and Essential Fatty Acids, vol. 79, no. 3-5, pp. 173-175, 2008. 

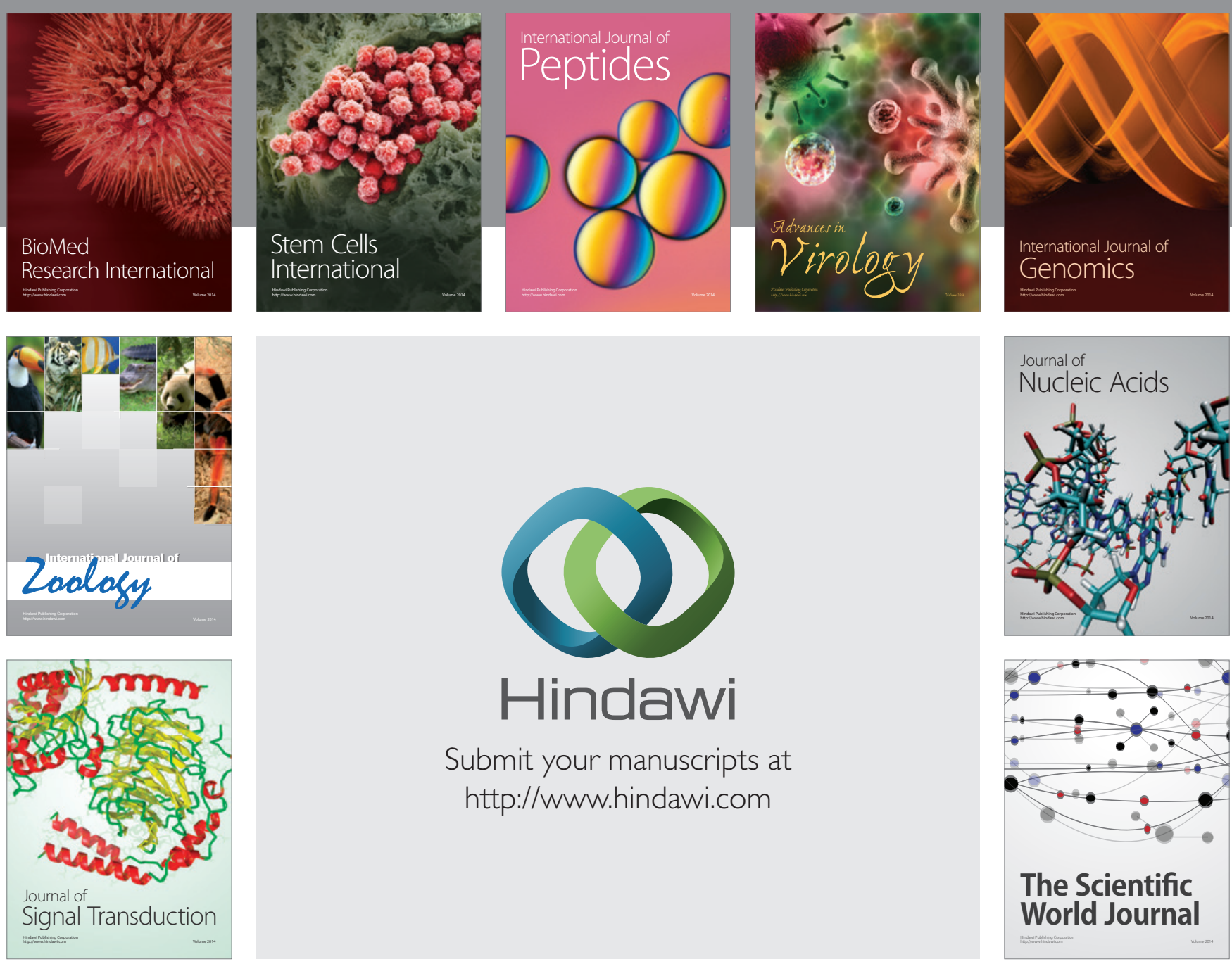

Submit your manuscripts at

http://www.hindawi.com
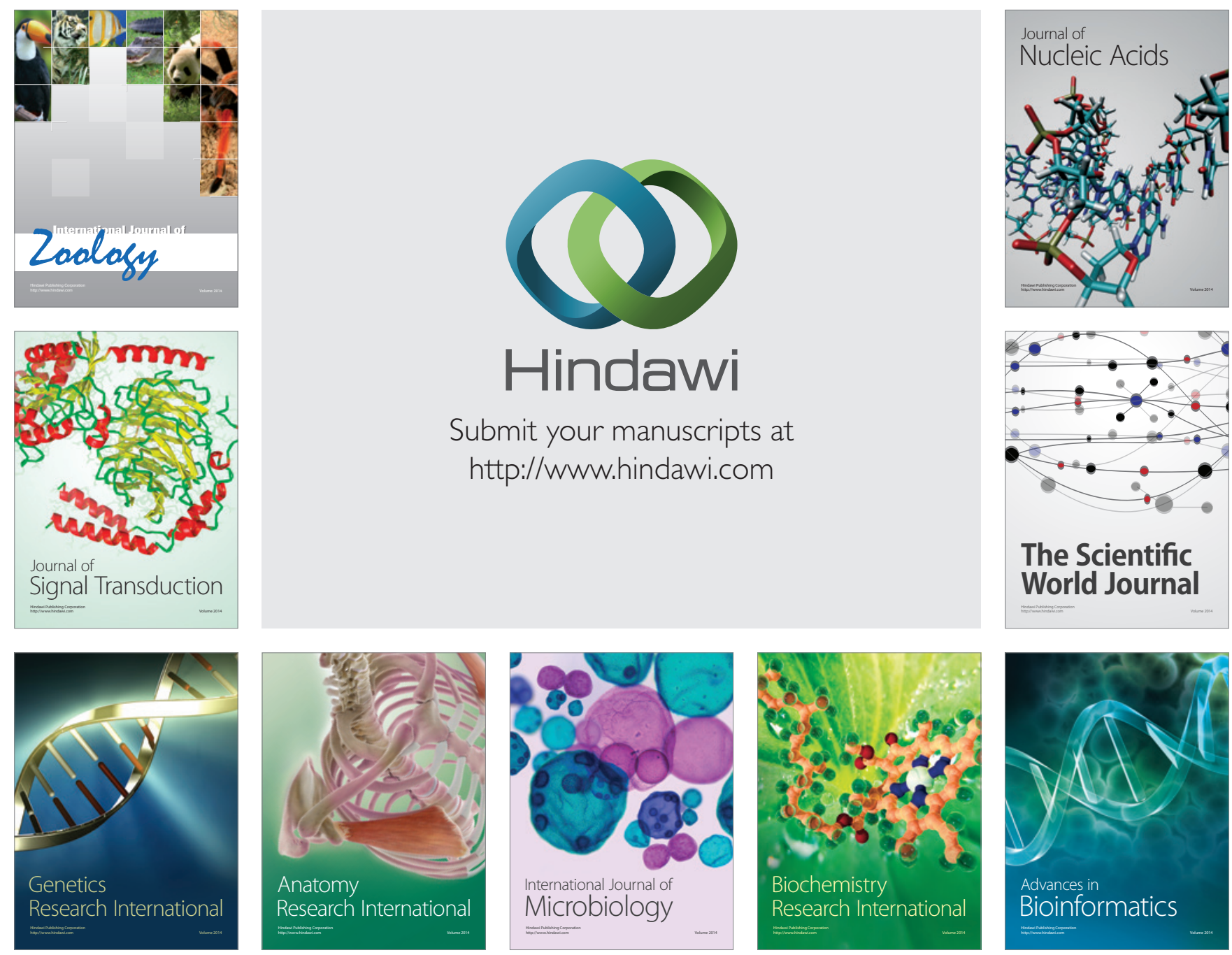

The Scientific World Journal
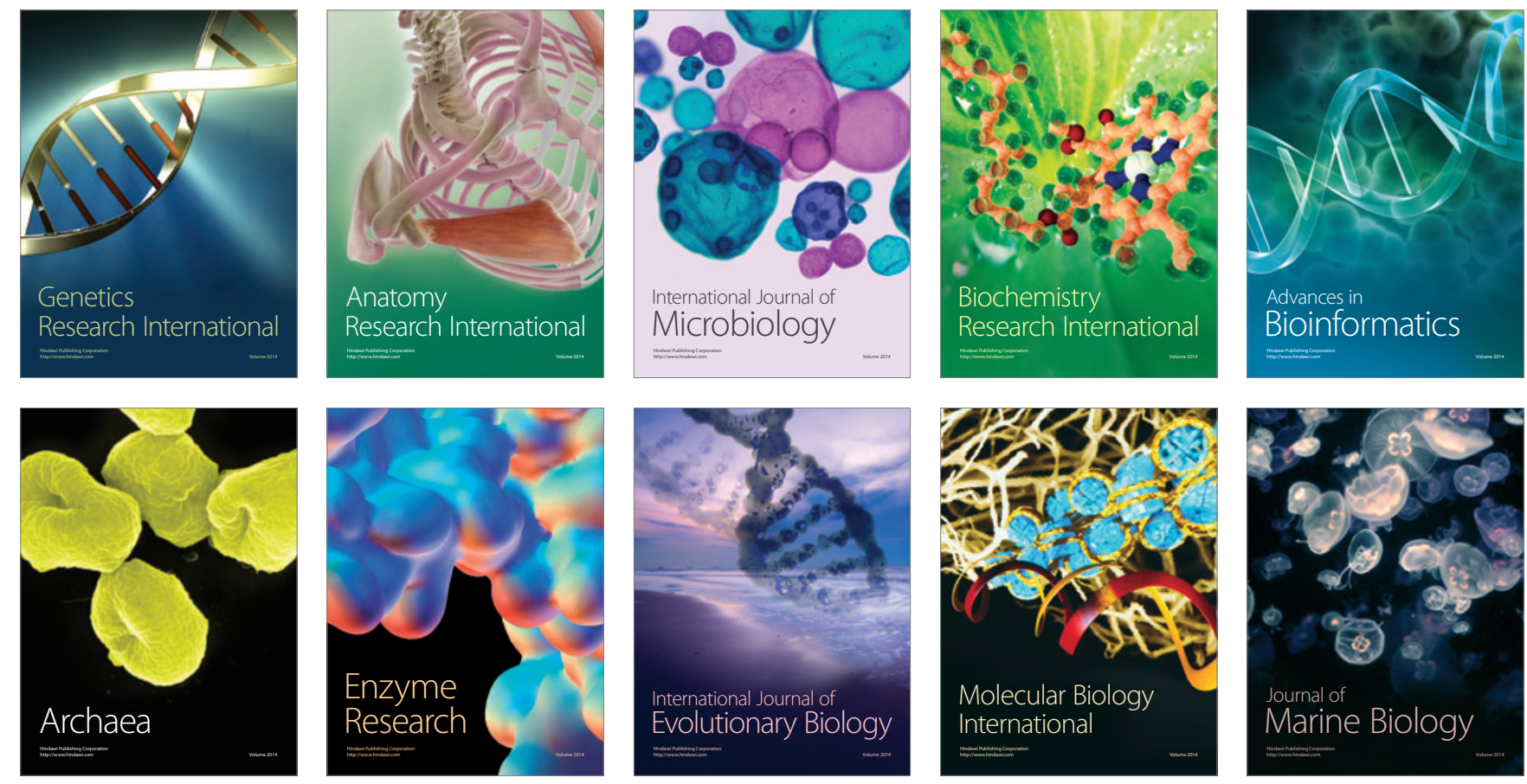